\title{
MUSICOLOGIA E HISTÓRIA. FRONTEIRA OU "TERRA DE NINGUÉM" ENTRE DUAS DISCIPLINAS? ")
}

\author{
Myriam Chimènes \\ Musicóloga, diretora de pesquisa do CNRS e do IRPMF
}

\begin{abstract}
Resumo
Poucos musicólogos consideram a Música como um fato histórico e orientam suas pesquisas para a história cultural. Por outro lado, os historiadores têm negligenciado a Música como objeto. Ao contrário da história da arte, que tem atraído particularmente o interesse de vários historiadores, a música não os atrai e parece ser ignorada por eles. Embora os historiadores se interessem por registros da pintura, eles sistematicamente evitam a Música, indicando que sua acessibilidade e legibilidade são demasiadamente complexas. Como podemos então explicar o fato da Música ter freqüentemente caráter secundário nos estudos dos historiadores? Em contrapartida, os musicólogos quando colocam seu objeto de estudo em contexto, não se preocupam como a Música poderia colaborar e participar da compreensão da história. Nós devemos, então, sugerir aos musicólogos outra leitura de suas fontes, para que eles questionem a Música de modo a lançar novas luzes sobre a História?
\end{abstract}

\section{Pallavras-Chave}

História • Musicologia • História Cultural

\section{Abstract}

On one hand, few musicologists consider Music as a historical fact, and thus orientate their researches towards cultural history. On the other, historians have neglected Music thus far. Contrary to art history, which has attracted the interest of others (historians in particular), music is not coveted, and seems to be ignored. How can we explain why Music stays too often on the sidelines of historians studies? Although historians are interested in picture records, they systematically avoid Music, as if accessibility and legibility where too difficult. Conversely, musicologists put their object of study in context, but are not concerned with what Music could bring to the understanding of history. Are we to suggest to musicologists another reading of their sources, so that they may question Music in order to shed new lights on History?

\section{Keywords}

History $•$ Musicologis $•$ Cultural History

${ }^{(*)}$ Artigo publicado originalmente na Revue de Musicologie, Société Française de Musicologie, Tome 84, № 1, 1998. Tradução, autorizada pela autora, realizada por José Geraldo Vinci de Moraes. 
O objetivo deste artigo é apresentar a recente discussão em torno de um campo de investigação que, durante muito tempo, permaneceu - como revela seu título - aberto e inexplorado por pesquisadores de duas disciplinas que julgo próximas e fronteiriças: a musicologia e a história. Com efeito, musicólogos e historiadores ignoraram-se reciprocamente durante décadas, como também a existência deste campo de pesquisa. Jamais eles reivindicaram ou disputaram sua propriedade assim como tardaram a se aventurar por essa área.

Como explicar que os historiadores que sabem interrogar as imagens ${ }^{1}$ tenham descartado durante tanto tempo a música do seu campo de pesquisa? Talvez por timidez face a um objeto de acessibilidade e de legibilidade diferentes. Por outro lado, como justificar que os musicólogos não tenham ouvido os historiadores generalistas e procurado inscrever a música nos quadros das pesquisas históricas? Provavelmente porque, mais músicos do que historiadores, não tivessem consciência da qualidade de seu objeto como fonte suscetível de contribuir à construção da história. Nosso propósito neste artigo é fazer um balanço sobre o tema e formular algumas proposições centradas no período contemporâneo, porque é ele que apresenta as lacunas mais evidentes.

Inicialmente pode-se dizer que as antigas atitudes das duas comunidades estão felizmente em vias de evolução. A título de exemplo, convém saudar duas iniciativas sintomáticas, que marcam os signos do progresso de cada uma das disciplinas. Na comunidade dos historiadores, a Sociedade de História Moderna e Contemporânea consagrou uma jornada de estudos ao tema "Artes e história”, com o propósito de interrogar as relações entre a história, as artes plásticas, a arquitetura, o cinema e também a música. Na nossa comunidade, a Sociedade Francesa de Musicologia organizou jornadas de estudos para debater a disciplina, seus métodos, objetos, objetivos e seu futuro² ${ }^{2}$ Estes sinais de abertura de ambas as partes e estas evoluções exploratórias não podem, no

\footnotetext{
${ }^{1}$ Cf. DORLÉAC, Laurence Bertrand. “L'histoire de l’art e les cannibales”. Vingtième siècle. Revue d'histoire, vol. 45, jan.-mars 1995, p. 99-108.

${ }^{2}$ As duas reuniões ocorreram no curso do mesmo ano de 1996. Jornadas de Estudos da SHMC, 13 de janeiro de 1996, Paris, Sorbonne, com a participação de Stèphane AudoinRouzeau (historiador), Laurence Bertrand Dorléac (historiadora e historiadora da arte), Myrian Chimènes (musicóloga), Antoine Debaecque (historiador) e Gerard Monnier (historiador da arte). Jornadas de Estudos de la SFM, Beaulieu-sur-mer, Villa Kerylos, 26-28 de setembro de 1996; tema: "Musicologia: objetivos e metodologias".
} 
entanto, indicar muito otimismo. Esta “terra de ninguém” é até o momento um terreno de encontro, cujo desbravamento está em curso e cuja conquista necessita das colaborações interdisciplinares.

\section{Musicólogos e história}

A musicologia é uma disciplina recente e polimorfa - as jornadas acadêmicas citadas logo acima testemunham isso -, deste modo, não pode ser nosso objetivo propor sua definição e nem ao menos enumerar as suas diversas facetas. Só o componente histórico nos interessa no contexto deste artigo. O verbete "Musicologia” da Encyclopédie de la musique, publicada em 1961, apresenta parcialmente reflexão nesta direção. Seu autor, François Lesure, adotou também um subtítulo polêmico, "Notas de processo". Eis um extrato significativo: "O trabalho musicológico considerado sério e valioso consistia, e ainda consiste, em estabelecer a biografia dos grandes músicos, descrever as influências que exerceram uns sobre os outros e traçar a história das formas e gêneros, geralmente relacionados ao nascimento e evolução do sistema tonal. Com o estudo desses grandes autores e da admiração por sua obra, descobrimos pouco a pouco que estes gênios foram influenciados por uma série de pequenos mestres, obrigando-nos também a estudá-los minuciosamente. Porém, aqueles que julgavam apreender o essencial, a saber, o estudo da linguagem musical, raramente passaram do estado puramente técnico de análise. Como se o estudo do bi-tematismo na sonata ou a introdução do cromatismo no madrigal tivessem em si mesmos uma significação cuja história se revelasse imediatamente. A situação teria talvez evoluído de modo diferente se os musicólogos tivessem mostrado mais interesse na evolução das disciplinas vizinhas. Mas simultaneamente eles foram tão despreocupados como aqueles que sempre ignoraram a musicologia. É por isso que geralmente os manuais de história da civilização não concedem espaço algum à música!”3 .

Sem pretender me alongar sobre a formação dos musicólogos, cuja "profissionalização” é recente, deve-se notar que o perfil daqueles que construíram a disciplina foi, sem dúvida, diferente das orientações indicadas por Lesure ${ }^{4}$.

\footnotetext{
${ }^{3}$ LESURE, François. “Musicologia”. In: Encyclopédie de la musique. Paris: Fasquelle, 1961. François Lesure retoma neste verbete uma problemática apresentada em um artigo anterior, “Musicologie et sociologie”. La revue musicale, n. 221, 1953, p. 4-11.

${ }^{4}$ Cf. CHIMÈNES, Myriam. "Histoire sans musique”. Bulletin de la société d'histoire moderne et contemporaine, n. 1-2, 1997, p. 12-21.
} 
Em seu texto, François Lesure acusava abertamente os musicólogos e denunciava precisamente o trabalho centrado exclusivamente sobre o objeto e desconectado do contexto geral. Não é inútil lembrar que Lesure é chartiste ${ }^{5}$ e que os chartistes são historiadores. E que foi discípulo de Pierre Francastel, professor da École Pratique des Hautes Études, vinculada ao grupo dos Annales e pioneiro de uma história cultural da arte.

Antes de dar início à reflexão propriamente histórica, muitos musicólogos passaram por um comportamento arqueológico e filológico, exumando repertórios e decifrando notações musicais. É nesta linha de trabalho que se situa a edição crítica, uma face da disciplina que conheceu impulso há dezenas de anos. Dominada por uma característica técnica, esta atividade, que se aproxima da restauração, estava ligada, entretanto, à filologia e à pesquisa histórica. O estudo conjunto de manuscritos musicais, de uma parte, e de fontes de arquivo, tais como as correspondências, os contratos de edição ou os artigos de imprensa, de outra parte, permitiu reconstituir a gênese das obras descritas nos prefácios destas edições críticas. Trata-se, entretanto, de uma concepção internalista da musicologia, que prevalece ainda nas monografias, e de uma história reduzida a seu objeto, construída exclusivamente sobre análise e evolução das formas.

Todos os pioneiros da disciplina, sem exceção, orientaram suas pesquisas para a música do passado e o interesse pela música contemporânea ficou limitado, para alguns deles, à organização de concertos ou à crítica musical. Isso explica sem dúvida a inexistência freqüente da música contemporânea nos manuais de história da música. Dois exemplos podem ilustrar muito bem a atitude de musicólogos para quem a história da música do tempo presente não é considerada sem importância ou valor, ao menos para a história “objetiva”. Podemos ler no capítulo escrito por Robert Bernard para La musique des origens à nos jours, publicada em 1946 sob a direção de Norbert Dufourcq, o seguinte: "O estudo da produção musical contemporânea coloca numerosos e complexos problemas. Só o recuo do tempo permite hierarquizar valores e julgar

\footnotetext{
${ }^{5}$ Derivado daquele que se formou na École des Chartes. Escola criada em 1821 para a formação de profissionais responsáveis pela gestão do patrimônio documental e artístico francês nos arquivos e bibliotecas públicas. Com o tempo tornou-se mais do que uma simples escola profissional, transformando-se no núcleo de discussão e defesa das regras da erudição e das ciências auxiliares. Atualmente é um curso superior de 3 anos que concede diploma de arquivista (NdT).
} 
os homens e suas obras com serenidade e situá-las com precisão. Face a um autor vivo, freqüentemente nos faz falta um ponto de referência, fato que nos impede perceber o essencial de sua obra e aquilo que dá sentido ao seu trabalho. Wagner antes de Tannhaüser, Debussy antes de Peléas, não foram para seus contemporâneos nem Wagner nem Debussy, tal como se apresentam atualmente para nós. Aquilo que, aos nossos olhos, anuncia o desabrochar do gênio, que contêm em germe, poderia muito bem escapar àqueles que apenas conheceram suas primeiras obras" ${ }^{\text {. }}$

Aproximadamente vinte anos mais tarde, uma advertência semelhante abre o capítulo consagrado à música contemporânea na França da Histoire de la musique, publicada sob a direção de Roland-Manuel: “a música contemporânea é uma matéria rebelde à atividade do historiador: a pretensão de construir uma visão objetiva sobre ela seria absurda. Ela só é ciência no passado. Só é possível fazer a história de uma época musical quando ela é superada e os períodos que a sucedem lhe garantem um lugar e um sentido ao fixá-la no tempo, por assim dizer”7.

Os autores destas linhas, respectivamente Robert Bernard e Gisele Brelet, revelam a marginalidade dos musicólogos, aparentemente ignorantes das correntes históricas que se desenvolviam na época, em particular a escola dos Annales ${ }^{8}$. Somente isso pode explicar o fato deles não conhecerem as contribuições de Marc Bloch; “É preciso conhecer o passado a partir do presente” e "conhecer o presente à luz do passado". "Este permanente vai-e-vem entre passado e presente permite enriquecer o conhecimento das sociedades antigas e esclarecer as sociedades atuais” ${ }^{\text {10 }}$. Esses musicólogos, entretanto, afir-

\footnotetext{
${ }^{6}$ BERNARD, Robert. “L'école française contemporaine jusqu’à 1940”. In: DUFOURCQ, Norbert (Dir.). La musique des origens à nos jours. Paris: Larousse, 1946, p. 398.

${ }^{7}$ BRELET, Gisèle. “Musique contemporaine en France”. In: Roland-Manuel (Dir.). Histoire de la musique. Paris: Gallimard, 1963. Encyclopédie de la Pléiade, vol. II, p. 1093.

${ }^{8}$ Iniciada nos anos 1930 por Lucien Febvre e Marc Bloch, essa corrente inovadora, que carrega o nome da revista, "recusa o evento e defende a longa duração, mudando a atenção da vida política para as atividades econômicas, a organização social, a psicologia coletiva e se esforça para aproximar a história das outras ciências humanas”, BOURDÉ, Guy; MARTIN, Hervé. Les Écoles historiques. Paris: Seuil, 1983, p. 215.

${ }^{9}$ BLOCH, March. Apologie pour l'histoire ou le métier d'historien. Paris: Armand Colin, 1949, réed. 1964, p. 11 e 13.

${ }^{10}$ BOURDÉ, Guy; MARTIN, Hervé. op.cit., p. 229.
} 
mam que a história necessita de afastamento no tempo. Mas o recuo temporal "não provém automaticamente da distância do tempo e não basta esperar para que ocorra. É preciso fazer uma história do tempo presente profissionalmente, a partir de documentos e não da lembrança, para colocar a justa distância”11. As posturas adotadas por esses musicólogos que não dissociam o julgamento da reflexão histórica indicam a amplitude da distância em relação ao desenvolvimento das ciências humanas.

\section{Historiadores e música}

François Lesure, no referido verbete, responsabilizava os musicólogos pelo isolamento da musicologia no seio das ciências humanas. Disso resultava, de acordo com ele, o lugar medíocre, insignificante, destinado à música nos livros de história. Na verdade talvez as responsabilidades devessem ser compartilhadas também com os historiadores.

No mesmo ano em que apareceu a obra dirigida por Norbert Duforcq, 1946, a editora Larousse publicou uma Histoire de France, sob a direção de Marcel Reinhard, professor da Sorbonne. No capítulo intitulado "La III République. Culture et civilization au début du XX $X^{e}$ siècle”12, na rubrica "artes plásticas”, após apresentar questões relativas à arquitetura, escultura e pintura, uma página é reservada à música (contendo uma justaposição de clichês sobre a música de Wagner, Franck, Saint-Saëns, d’Indy, Debussy, Fauré, Roussel e Ravel). Além do lugar ridículo concedido a ela, esta aproximação terminológica é reveladora do pouco caso que o historiador fazia da música ${ }^{13}$.

\footnotetext{
${ }^{11}$ PROST, Antoine. Douze leçons sur l'histoire. Paris: Seuil, 1996, p. 95.

${ }^{12}$ REINHARD, Marcel (Dir.). Histoire de France. Paris: Larousse, 1946, Tome 2: de 1715 à 1946.

${ }^{13}$ Notar-se-á a esse propósito a ambigüidade da terminologia. A história da arte é exclusivamente a das artes plásticas e das belas artes, não incluindo tradicionalmente a música. No entanto, durante muito tempo, o vocabulário administrativo esvazia o termo música em benefício do termo belas-artes, na qual a música se encontra disfarçada. "Não é supérfluo interrogar-se sobre a definição do termo belas-artes: a música, a pintura, a escultura, a arquitetura, a eloqüência da poesia antes de tudo, e subsidiariamente a dança” (Dictionnaire Littré, 1863); “artes que têm por objeto a representação do belo” (Dictionnaire Robert); "nome dado a certas artes plásticas, principalmente a pintura e a escultura, e por extensão a música e algumas coreografias” (Dictionnaire Larousse). Na realidade a música não é correntemente associada às belas-artes. A Escola de Belas-artes jamais se preocupou com o ensino musical. É o Conservatório Nacional de Música que sempre teve o monopólio desta formação. Podemos constatar uma estranha analogia entre esta realidade e a surdez dos historiadores.
} 
Na sua Histoire culturelle de la France XIX $X^{e} X X^{e}$ siècles, publicada em 1974, Maurice Crubellier consagrou algumas páginas à “música moderna” no capítulo "la contestation dans l'art". Ele comparou as artes visuais e sonoras, sublinhando as diferenças naturais entre os dois domínios artísticos: “a pintura parte da realidade que ela interpreta; a música, sem dúvida, constrói um mundo seu. Mas não se deve forçar essa oposição. O que o mundo atualmente revela é justamente uma aproximação profunda entre a música que retorna à realidade sonora - se aplica em tirar novos elementos fabricados a partir de uma linguagem mais rica, nova e melhor adaptada à sua mensagem - e a pintura e a escultura que se libertam de uma submissão mais convencional aos objetos, ou às fisionomias, ou às paisagens, para reconstruírem livremente suas obras a partir de elementos muito variados, mas realmente selecionados”14. Para credenciar suas afirmações, Crubellier nos envia aos especialistas, em particular a Henry Barraud, que cita abundantemente ${ }^{15}$.

Na obra coletiva Histoire de France ${ }^{16}$ (de 1985) dirigida por Jean Favier, no quinto volume (1851-1918) intitulado La France des patriotes, capítulo "La République face aux intellectuels”, escrito por François Caron, há apenas duas páginas consagradas à música francesa. Trata-se de uma condensação de informações dispersas retiradas de duas obras utilizadas pelo autor: La musique française, de Norbert Dufourcq, e La musique en France, de la Révolution à 1900, de Danièle Pistone ${ }^{17}$. Já o sexto volume, Notre siècle (1918-1991), escrito por René Rémond com a colaboração de Jean-François Sirinelli, traz uma definição pertinente sobre história cultural que poderia ser útil aos musicólogos: "Esta história não pode se dissociar da história social e das mentalidades. Pintor, o historiador deve se tornar também sociólogo e antropólogo. Simplesmente porque toda atividade criadora, dentro de sua recepção em um grupo dado, revela a emoção e o gosto, que são eles mesmos também objetos da história. E esta criação se enraíza a todo o momento em um terreno social e político

\footnotetext{
${ }^{14}$ CRUBELLIER, Maurice. Histoire culturelle de la France XIX ${ }^{e}$ - XX $X^{e}$ siècles. Paris: Seuil, Armand Colin, 1974.

${ }^{15}$ BARRAUD, Henry. Pour compreende les musiques d'aujourd'hui. Paris: Seuil, 1968.

${ }^{16}$ CARON, François. “La France des patriotes (1815-1918)”. In: FAVIER, Jean (Dir.). Histoire de France. Tome 5, Paris: Fayard, 1985.

${ }^{17}$ DUFOURCQ, Nobert. La musique française. Paris: Larousse, 1949; PISTONE, Danièle. La musique en France de la Révolution à 1900. Paris: Champion, 1979.
} 
com o qual ela mantém relações de duplo sentido”18. Jean-François Sirinelli indica ainda com justeza e clareza as direções que podem orientar os musicólogos inquietos que ambicionam enriquecer seus questionamentos e alargar seu campo de pesquisa, ao mesmo tempo em que podem contribuir para a construção da história cultural ${ }^{19}$.

A Histoire de France, dirigida por André Burguière e Jacques Revel, publicada em 1993, contém um volume com o título Les formes de la culture. No capítulo “Ruptures et figures contemporaines", a autora Madeleine Rebérioux evoca a música e centra seu assunto nos corais. Referindo-se ao trabalho de Philippe Gumplowitz, ela lembra que em 1830, para garantir uma moral aos trabalhadores, lutou-se notadamente contra o clima deletério das tabernas e a música teve a capacidade de selar um contrato social, os corais (alguns criados pelos patrões) acabaram por ser úteis para a paz social. Madeleine Rebérioux sublinha que "a música, como prática cultural coletiva, decididamente entrou na era das multidões”20. Estes exemplos não são caricaturas. São característicos. Eles provam que, para os historiadores, a música não foi durante muito tempo um objeto de estudo e em conseqüência não merece mais que um espaço ínfimo em suas obras. E não é surpreendente, pois, constatar que o historiador cita eventualmente o musicólogo para disfarçar sua legitima incompetência, mas que ele não se iluda ao solicitar essa ajuda, pois ela será sempre temporária e precária.

\section{Comportamentos convergentes}

Os musicólogos geralmente examinam o contexto para esclarecer o objeto de sua especialidade, mas não se interrogam inversamente sobre aquilo que a música pode fornecer para a compreensão da história da qual ela faz parte. Não é de se surpreender, portanto, que a musicologia histórica não tenha evoluído mais sob influência da etnomusicologia. Com efeito, numerosos etnomusi-

\footnotetext{
${ }^{18}$ RÉMOND, René. "Notre siècle 1918-1991”. Avec la collaboration de Jean-François Sirinelli. In: FAVIER, Jean (Dir.). Histoire de France I. Tome 6. Paris: Fayard, 1985, p. 243.

${ }^{19}$ Ver igualmente RIOUX, Jean-Pierre; SIRINELLI, Jean-François. Pour une histoire culturelle. Paris: Seuil, 1997.

${ }^{20}$ BURGUIÈRE, André ; REVEL, Jacques (Dir.). Histoire de France. Volume 4: Les formes de la culture. Paris: Seuil, 1993, p. 426.
} 
cólogos estudam a música como parte integrante das manifestações sociais e religiosas da sociedade. O soberbo livro de Gilbert Rouget, La musique et la transe, é uma obra que marca e nos faz refletir sobre esse assunto ${ }^{21}$. Podemos, no entanto, notar outros progressos desde a publicação do artigo de François Lesure. Alguns trabalhos musicológicos que abordam o período barroco, a Revolução e o século XIX, foram consagrados não apenas à música, mas também à vida musical, testemunhando que o interesse dos musicólogos não está mais restrito tão somente à criação musical, mas se ampliou também em direção à recepção. Neste sentido, a obra de Joël-Marie Fauquet, Les sociétés de musique de chambre à Paris, de la Restauration à $1870^{22}$, baseada na sua tese orientada por François Lesure, pode ser considerada como pioneira na medida que leva em consideração as dimensões musicológica, histórica, estética e sociológica do objeto.

Há quinze anos a concepção da disciplina se alargou; em particular sob o impulso do compositor e filósofo Hugues Dufourt, que criou no Centro Nacional de Pesquisa Científica (CNRS) um laboratório cujo programa tinha como objetivo desenvolver pesquisas em história social da música. O primeiro resultado dos trabalhos desenvolvidos no Seminário “Da Idade Média a nossos dias: as relações que são instituídas no curso da história ocidental, entre a arte musical e a vontade política” foi o volume La musique et le pouvoir. Na introdução, Hugues Dufourt lembra que "a música é uma linguagem coletiva. Como as outras artes, ela elabora os signos sensíveis pelos quais os homens de um momento do mundo revelam sua vontade e esperança. A obra literária, a obra plástica e a obra musical não revelam as tensões e os antagonismos profundos da realidade histórica? Então, uma verdadeira teoria da música deve mostrar como a sensibilidade dos homens de uma sociedade dada pode se simbolizar pela escrita musical."23

\footnotetext{
${ }^{21}$ ROUGET, Gilbert. La musique et la transe. Esquisse d'une théorie générale des relations de la musique et de la possession. Paris: Gallimard, 1980.

${ }^{22}$ FAUQUET, Joël-Marie. Les sociétes de musique de chambre à Paris de la Restauration à 1870. Paris: Aux Amateurs de Livres, 1986.

${ }^{23}$ FAUQUET, Joël-Marie (Dir.). La musique et le pouvoir. Paris: Aux Amateurs de Livres, 1987, p. 15.
} 
O XVII ${ }^{\circ}$ congresso da Sociedade Internacional de Musicologia, ocorrido em Londres em agosto de 1997, revelou toda essa tendência favorável às mudanças. Ao escolher o tema "Musicologia e disciplinas irmãs" ele confirmou que a musicologia ambiciona sair de seu campo limitado.

Os sinais de interesse por mudanças são igualmente sensíveis entre os historiadores. Na sua obra consagrada à cultura na Frente Popular, Pascal Ory dedica um capítulo importante à música, no qual sublinha que ela é a "arte considerada a mais mediocremente influenciável pela conjuntura política”24. Responsável pelo Centro de História Cultural das Sociedades Contemporâneas da Universidade de Versailles-Saint-Quetin-en-Yvelines, Pascal Ory incluiu a música no campo de pesquisa da história cultural e, conseqüentemente, orienta trabalhos de alunos nesta área, como, por exemplo, as dissertações e teses com temas sobre as juventudes musicais na França, a política musical da França entre 1966 e 1974, ou o jazz na França entre 1944 e 1963²5. Do mesmo modo, a Escola de Chartes também apresenta há anos um quadro de teses sobre música, orientadas por François Lesure.

\section{Reencontros}

As experiências interdisciplinares marcam os resultados das atividades convergentes. Elas são recentes, mas determinantes na medida em que concretizam uma vontade mútua de colaboração. Novamente alguns exemplos significativos merecem ser citados.

Dois colóquios marcantes, com essas características, ocorreram na Alemanha. O primeiro, “O wagnerismo na música e na cultura musical francesa (1861 e 1914)”, ocorreu em Berlim em 1995 e foi organizado pelo Centro Marc Bloch

\footnotetext{
${ }^{24}$ ORY, Pascal. La belle illusion. Culture et politique sous le signe du Front Populaire 19351938. Paris: Plon, 1994. A título de comparação, o capítulo "arts plastiques” comporta 53 páginas e o capítulo “musique” 45 páginas.

${ }^{25}$ SIMION, Catherine. L'Histoire des Jeunesses musicales de France (1940-1971), une initiation musicale pour les Français. Dissertação de mestrado, Université de Paris X Nanterre, orientada por Philippe Levillain e Pascal Ory, 1991; GRANDGAMBE, Sandrine. La politique musicale de la France 1966-1974. Dissertação de mestrado em história contemporânea, Université de Paris X-Nanterre, orientada por Philippe Levillain e Pascal Ory, 1991-1992; TOURNÈS, Ludovic. Le jazz en France (1944-1963): histoire d'une acculturation à l'époque contemporaine. Tese de doutorado, Université de Versailles-Saint-Quetin-en-Yvelines, orientada por Pascal Ory, 1997.
} 
e pelo Instituto de Musicologia da Universidade Humbold ${ }^{26}$. Sob responsabilidade conjunta de musicólogos e historiadores, ele reuniu ainda filósofos, historiadores da arte e da literatura para tratar da influência de Wagner sobre os músicos franceses e do wagnerismo como fenômeno cultural, com suas conseqüências sociais e as implicações políticas no debate estético. O segundo, intitulado "Concerto e público: mudanças da vida musical na Europa de 1780 a 1914”, se reuniu em Göttingen em 1996 ${ }^{27}$. Igualmente pluridisciplinar, ele testemunhou uma preocupação de abertura semelhante com a do congresso do ano anterior e, deste modo, pretendia "se inscrever em um projeto de história social e de história das práticas culturais” com o "objetivo de lançar uma reflexão global sobre a longa duração, que comporta uma questão tão importante que ela contém em essência nossa própria relação com a música”. Dentro deste quadro temporal, cinco conjuntos temáticos foram reunidos: "editores, comerciantes de música, imprensa e desenvolvimento da vida musical”; "organização: dos mecenas aos empresários de concerto”; "sociedades de concertos e assinaturas”; "música e espaço”; "o público e sua escuta: componentes e apropriações” ${ }^{28}$.

Foi com este mesmo espírito interdisciplinar que surgiu o grupo de pesquisa sobre a "Vida musical na França durante a Segunda Guerra Mundial” ${ }^{29}$. Ele é resultado da colaboração estabelecida entre dois laboratórios do CNRS, um de musicologia (Instituto de Pesquisa sobre o Patrimônio Musical na França) e outro de história (Instituto de História do Tempo Presente), e seu objetivo é reunir as competências dos representantes das duas disciplinas para refletir sobre o tema.

${ }^{26}$ Der "Wagnérisme” in der französischen Musik und Musikkultur (1861-1914). Berlin, 810 de junho, colóquio organizado pelo Centro Marc Bloch e pelo Instituto de Musicologia da Universidade Humbold. Comitê científico: Étienne François e Reinhart Meyer-Kalkus, historiadores, Hermann Danuser, Annegret Fauser e Manuela Schwartz, musicólogos.

${ }^{27}$ Concert et public: mutation de la vie musicale de 1780 à 1914. (Allemagne, France, Angleterre), Göttingen 27-29 de junho de 1996, colóquio organizado pela Missão Histórica Francesa na Alemanha (Göttingen), em cooperação com o Max-Planck-Institut für Geschichte e o Centro de Estudos e de Pesquisas Alemãs da Escola Prática de Altos Estudos em Ciências Sociais (EHESS - Paris). Responsáveis: Hans-Erich Bödecker, Patrice Veit e Michael Wener.

${ }^{28}$ Cf. anuncia o colóquio CIRAC Fórum (Centro de Informação e de Pesquisa sobre a Alemanh Contemporânea), nº 33, abril de 1996.

${ }^{29}$ Esta colaboração é instaurada por iniciativa comum de Henry Rousso e minha. Os trabalhos deste grupo de pesquisa desembocaram em um colóquio co-organizado por dois laboratórios que ocorreu em 28, 29 e 30 de janeiro de 1999, no Conservatório Nacional Superior de Música e Dança de Paris, no La Villete. 


\title{
Para uma contribuição à história cultural
}

Esta apresentação sumária mostra uma notável evolução na concepção da musicologia, que significa, assim esperamos, o fim da concentração da disciplina sobre ela mesma e a abertura de diálogo com as outras disciplinas das ciências humanas. Como veremos a seguir, as formas de questionamento e as periodizações estabelecidas contribuíram muito para a definição desta evolução.

\begin{abstract}
"Se não há história sem fatos, não há também história sem questões; as questões sempre tiveram lugar decisivo na construção da história [...]. É a questão que constrói o objeto histórico, procedendo a uma reorganização original no universo sem limite dos fatos e dos documentos possíveis. Do ponto de vista epistemológico, ela ocupa uma função fundamental, no sentido etimológico do termo, pois é ela que funda e constitui o objeto histórico. Em certo sentido, uma história vale o que vale sua questão. Surge daí a importância e a necessidade de colocar o problema da questão”30.
\end{abstract}

A afirmação de Antoine Prost se encaixa perfeitamente em nossa proposta. A música oferece um conjunto de investigações particularmente rico, que não se reduz a um criador e a uma obra. Seus mediadores, que são os instrumentos e intérpretes (profissionais e amadores), seus modos de difusão (edição, concertos, discos, rádio, televisão alternando com a imprensa) merecem ser igualmente pesquisados e questionados. Algumas dissertações de mestrado começaram a tratar destes temas, mas nenhum trabalho musicológico mais aprofundado foi ainda publicado. Entretanto, alguns sociólogos penetraram por essas brechas abertas pelos musicólogos, como testemunham notadamente os trabalhos de Frédérique Patureau ou Pierre-Michel Menger ${ }^{31}$. Outro tema determinante que não pode ser ignorado e necessita de mais reflexão e questionamentos dos especialistas do século XX - relativamente pouco numerosos ainda - é o papel da gravação na difusão e recepção da obra. Determinantes para o processo de democratização da música, o disco e o rádio transforma-

\footnotetext{
${ }^{30}$ PROST, Antoine. Op.cit., p. 79.

${ }^{31}$ PATUREAU, Frédérique. Le Palais Garnier dans la société parisienne, 1875-1914. Liège: Mardaga, 1991; MENGER, Pierre-Michel. Le Paradoxe du musicien, le compositeur, le mélomane et l'État dans la société contemporaine. Paris: Flamarion, 1983.
} 
ram a carreira de compositores e intérpretes, permitindo a difusão das obras, aproximando-as de um público consideravelmente mais amplo, fenômeno sem precedentes na história da música. Estes poucos exemplos, constituem não só um vasto canteiro de pesquisas necessário para a construção da história da música no século XX, como também colaboraram a seu modo para inscrevêla nos quadros da história cultural.

Os questionamentos em torno da periodização constituem o outro elemento determinante na evolução da disciplina e, conseqüentemente, de nossas reflexões $^{32}$. No século XVII, por exemplo, o estado de dependência do músico em relação ao político era tão forte que não pôde ser ignorado pelos estudiosos, sendo o caso mais marcante o duo formado por Lully-Luís XIV. Este fato legitima as pesquisas sobre a música como acessório do poder monárquico. Pois bem, o estudo do período contemporâneo deve obedecer a uma dinâmica semelhante. A história política e institucional atual deve ser levada em consideração, o que não exclui, claro, que ela seja cruzada com a história das correntes estéticas. Inscrever uma pesquisa musicológica no tempo político pode ajudar a desenvolver de maneira proveitosa os estudos sobre os diversos domínios artísticos e contribuir também para a elaboração da história cultural. Trabalhos recentes revelam essa nova dinâmica ${ }^{33}$, como o do grupo de pesquisa sobre A vida musical na França durante a Segunda Guerra Mundial.

Insistiremos um pouco mais sobre este último exemplo significativo. A vida cultural nos anos negros da Segunda Guerra proporcionou nos últimos anos o surgimento de estudos históricos essencialmente centrados na literatura, artes plásticas, teatro e cinema. A música permaneceu ausente deste campo de pesquisas, evocada às vezes apenas de maneira episódica ${ }^{34}$. Foram alguns musicólogos que tomaram a iniciativa de preencher esta lacuna e solicitaram a

\footnotetext{
${ }^{32}$ Cf. PROST, Antoine. "Les temps de l'histoire”. In: op. cit., p. 101-123.

${ }^{33}$ Cf. a título de exemplos: CHIMÈNES, Myriam. "Le budget de la musique sous la III République”. In: DUFOURT, Hugues; FAUQUET, Joël-Marie (orgs.). La musique: du théorique au politique. Paris: Klincksieck, 1991, p. 261-312; DUCHESNEAU, Michel. "La musique française pendant la Guerre 1914-1918: autour de la tentative de fusion de la Société Nationale de Musique e de la Société Musicale Indépendante”, Revue de musicologie, Vol. 82, n.1, p. 123-153, 1996; GEYER, Myriam. La Vie musicale à Strasbourg sous l'Empire Allemand (1879-1918). Tese da École des Chartes, orientada por François Lesure, 1998.

${ }^{34}$ Cf. RIOUX, Jean-Pierre (Dir.). La vie culturelle sous Vichy. Bruxelles: Complexe, 1990. Esta obra não contém nenhum capítulo sobre a música, e sua ausência não se nota.
} 
colaboração de historiadores especialistas no período. Uma equipe pluridisciplinar se reuniu então para trabalhar em torno de alguns grandes eixos de pesquisa. Uma das chaves essenciais desta investigação coletiva era compreender o impacto da música alemã na zona ocupada pelos nazistas, uma vez que desde o final do século XIX ela sofria com as reações protecionistas da França, particularmente à música de Wagner. Durante o domínio francês, a propaganda nazista promoveu e difundiu a música alemã na zona ocupada. O exame minucioso dos arquivos alemães, de um lado, e os programas de concerto e de rádio, por outro lado, deveriam permitir medir os efeitos desta política alemã. Neste contexto, a política musical do Governo de Vichy também deveria ser analisada, tanto na forma de sua continuidade na Frente Popular, como de sua projeção no período pós-guerra. Alguns indícios são bem marcantes, como a multiplicação das ações do Estado, da atuação dos compositores, o nascimento das Juventudes Musicais e do movimento “coração contente” ou a criação do Departamento de Música da Biblioteca Nacional. Aliás, esse estudo da vida musical parisiense trata ao mesmo tempo do funcionamento das instituições (como o Conservatório e a Ópera) e atividades das associações sinfônicas, como também das manifestações específicas do período de Ocupação, como os concertos da Radio-Paris ou os Concertos de la Pléiade, organizados pela N.R.F. a partir de fevereiro de 1943. O quadro da vida musical na França entre 1939 e 1945 é completado com a eleição de algumas outras cidades escolhidas em função da importância de sua tradição musical; algumas da zona de ocupação (Rennes, Bordeaux), da zona livre (Vichy, Marseille) e da zona anexada (Strasbourg). Porém, as pesquisas não estão limitadas à música considerada séria e abordam igualmente o jazz e a canção. Por fim, os estudos complementares relativos ao rádio e à imprensa (em particular L'information musicale, revista publicada entre novembro de 1940 e maio de 1944, e a imprensa clandestina) concedem um caráter transversal que une e dá forma ao conjunto de objetos investigados. Estas inúmeras pesquisas constituem um conjunto prévio indispensável de informações, que permitirá o estabelecimento de uma síntese, que poderá avaliar as perseguições, medir o engajamento e definir uma estética da época. Na realidade, elas fazem parte de uma corrente historiográfica que estuda os aspectos culturais da França sob Vichy (e não de Vichy) e que avalia o impacto do "tempo de guerra” sobre a carreira dos músicos, a recepção das obras, algumas formas de sociabilidade, a freqüência dos concertos ou a prática amadora, todas elas devendo ser consideradas como derivadas das dificuldades da vida cotidiana na época da ocupação. 
Até a formação deste grupo de pesquisa, estes objetos eram tipicamente situados na “terra de ninguém”, isto é, negligenciados ou ignorados pelas duas disciplinas. Ele mostra bem que a história da música é ao mesmo tempo o objeto de si mesmo, mas também de seus criadores, mediadores e consumidores, fazendo parte de uma história cultural mais abrangente. Ele revela o problema de situar a história da música no tempo político, sem descartar os aspectos econômicos, sociológicos ou estéticos. A história da vida cultural deste período não pode se limitar ao estudo da vida musical. A história da música não pode omitir as interrogações relativas à incidência do "tempo de guerra” sobre a criação e recepção musical.

Retornando ao verbete de François Lesure, ali ele afirma que “O objetivo supremo seria evidentemente descobrir aquilo que o musical ensina ao homem e que seja diferente daquilo que a linguagem, a religião, o direito nos ensina dele”35. Para alcançar essas orientações seria preciso sugerir aos musicólogos uma outra leitura das fontes, a fim de que eles não questionem mais a história somente para saber o que ela contém de música, mas que eles interroguem também a música para compreender aquilo que talvez só ela possa restituir à história? Seria preciso desafiar os historiadores a aprender a ler uma partitura? Seria preciso promover as colaborações interdisciplinares?

A surdez dos historiadores está em via de cura. Quanto aos musicólogos, eles mostram vontade de sair de seu isolamento. Neste sentido, desejamos que seja declarada aberta uma fronteira que não precise ceder à força, pois ela é antes de tudo muito porosa. Convém conduzir as investigações por este tipo de território. Marc Bloch preconizava a organização do trabalho em equipe agrupando os especialistas de diversas disciplinas ${ }^{36}$, argumentando o fato de que "se não é possível um mesmo homem (historiador) alcançar a multiplicidade de competências, devemos considerar uma aliança de técnicas praticadas por eruditos diferentes” ${ }^{37}$. Os musicólogos têm de dar sua parte na construção da história cultural.

\footnotetext{
${ }^{35}$ LESURE, François. Op. cit.

${ }^{36}$ É assim que nasceu a VI ${ }^{\mathrm{a}}$ Seção da Ecole Pratique des Hautes Études, transformada em Ecole des Hautes Études en Sciences Sociales em 1975.
}

${ }^{37}$ BLOCH, Marc. Op. cit., p. 28. 